\title{
Healthcare professionals' acceptance of BelRAl, a web-based system enabling person-centred recording and data sharing across care settings with interRAl instruments: a UTAUT analysis
}

\author{
Dirk Vanneste $^{1 *}$, Bram Vermeulen $^{1}$ and Anja Declercq ${ }^{2}$
}

\begin{abstract}
Background: Healthcare and social care environments are increasingly confronted with older persons with long-term care needs. Consequently, the need for integrated and coordinated assessment systems increases. In Belgium, feasibility studies have been conducted on the implementation and use of interRAl instruments offering opportunities to improve continuity and quality of care. However, the development and implementation of information technology to support a shared dataset is a difficult and gradual process. We explore the applicability of the UTAUT theoretical model in the BelRAI healthcare project to analyse the acceptance of the BelRAI web application by healthcare professionals in home care, nursing home care and acute hospital care for older people with disabilities.
\end{abstract}

Methods: A structured questionnaire containing items based on constructs validated in the original UTAUT study was distributed to 661 Flemish caregivers. We performed a complete case analysis using data from 282 questionnaires to obtain information regarding the effects of performance expectancy (PE), effort expectancy (EE), social influence (SI), facilitating conditions (FC), anxiety (ANX), self-efficacy (SE) and attitude towards using technology (ATUT) on behavioural intention (BI) to use the BelRAI web application.

Results: The values of the internal consistency evaluation of each construct demonstrated adequate reliability of the survey instrument. Convergent and discriminant validity were established. However, the items of the ATUT construct cross-loaded on PE. FC proved to have the most significant influence on BI to use BelRAl, followed by SE. Other constructs (PE, EE, SI, ANX, ATUT) had no significant influence on Bl. The 'direct effects only' model explained 30.8\% of the variance in $\mathrm{BI}$ to use BelRAl.

Conclusions: Critical factors in stimulating the behavioural intention to use new technology are good-quality software, interoperability and compatibility with other information systems, easy access to computers, training facilities, built-in and online help and ongoing IT support. These findings can be used by policy makers to maximise the acceptance and the success of new technology. For researchers, the conclusions of the original UTAUT study with regards to the item and scale construction should not be copied blindly across different information systems. A bottom-up approach is preferred when building upon the UTAUT model.

Keywords: BelRAI, InterRAI, Older people, Person-centred, Computerisation, Data sharing, Integrated care, UTAUT, Technology acceptance, SEM, PLS

\footnotetext{
* Correspondence: dirk.vanneste@med.kuleuven.be

'Elderly Care Research Unit at LUCAS, KU Leuven, Kapucijnenvoer 39, 3000

Leuven, Belgium

Full list of author information is available at the end of the article
} 


\section{Background}

The 21st century is the century of the 'ageing population'. In Belgium (population 2011: 11 million), there are now 1.88 million people aged 65 and older which equals $17 \%$ of the population [1]. In 2020, they will be 2.22 million, which is plus $20 \%$. Over the next 10 years the number of people over 80 will grow to nearly 578,500 , compared with 479,000 in 2011 [2].

As people live longer, healthcare environments are increasingly confronted with older persons, characterised by chronic conditions and/or comorbidities necessitating long-term care [3-6] and rising costs. There is also a substantial shift away from institutional caregiving. This evolution increases the complexity of caregiving since multiple service providers are delivering care to individuals $[3,7,8]$. The need to receive support from multiple service providers has important implications for persons with complex care needs [9].

As these people transfer between settings, accurate communication and sharing of crucial information is fundamental in providing high quality care [10]. A lack of information (transfer) can result in errors [11], increased assessment burden, and frustration among care recipients and their supporting network [12]. Deficient information transfer or communication can result in uncoordinated care, adverse events and iatrogenic complications influencing morbidity, mortality and hospital outcomes [10,11]. It appears that clinical information systems that typically have been designed to support single service providers in one setting no longer meet the necessary requirements [8].

As people migrate through this maze of healthcare providers, the need for integrated and coordinated assessment systems providing comparable information increases [13], as does the need for service provisions that overcome barriers [3,8,14-16]. The importance of good communication in healthcare environments [17] to enable person-centred care and increase safety cannot be emphasised enough. Collected data must be available and useful to those who have to decide at the personal, clinical, managerial, and public policy levels $[3,18]$. In complex healthcare and social care systems in which people with the same needs might receive different services in different sectors and in which changes in one subsystem might affect other subsystems, thinking at the system level is crucial. To this end, it is necessary to have an integrated, standardised and computerised collection of information in a language that is clear and understandable to all users $[3,8,19,20]$.

The interRAI suite of instruments [21] addresses the changing strengths, preferences and needs of vulnerable people rather than the organisation which provides services at a single point in time $[6,8]$. This 'third generation' multi-domain suite of compatible instruments has the potential to transfer and share high quality person- centred information and to compare people, services and outcomes across settings [12,22-26].

Although these instruments provide opportunities to improve continuity of care, as well as efficiency and quality of care [27-37], they cannot reach their full potential with paper-based recording only. Paper-based recording has severe limitations: it is applicable only to slow, manual processing, it is difficult to share, it may lack information concerning the history of treatment, it is centred upon institutional boundaries, it is vulnerable to errors, it lacks interoperability with other information systems and its information may not be presented in ways relevant to specific care contexts [38]. Moreover, the complex algorithms of the interRAI suite of instruments that generate decision support outcomes and guidelines are highly dependent on automation.

These problems can only be addressed by the use of computer-based information technologies $[8,19]$. Information technology (IT) is already being used to prevent human error in healthcare and to improve patient care outcomes worldwide. In 2000, the Institute of Medicine in Washington DC recommended increasing efforts to incorporate information technology into the delivery of patient care [39].

In Belgium, web-based software has been developed to support the use of the interRAI instruments in different settings and in different languages ${ }^{\mathrm{a}}$. This software has been tested and evaluated. As, to our knowledge, there is no evidence of a fully computerised set of interRAI suite instruments throughout the whole world, this research can be considered innovative.

However, developing and implementing information technology to support a shared dataset is a difficult, slow and gradual process [40]. There is also a gap between the two different professional approaches. On the one hand, information and communication technologies (ICT) scientists may have the technical skills to develop an application, but they are unlikely to fully understand how the application must operate in order to support the organisation. On the other hand, healthcare organisations may be able to identify and express the 'what', 'when', 'for whom' and 'where' issues concerning an application to support their goals, but they may not have the technical skills to make it happen [41]. Consequently, in order to achieve a successful implementation, substantial challenges have to be tackled [42]. There is a need for good-quality software, ongoing IT support, access to computers, and a degree of computer literacy in care organisations $[8,19,43]$. Moreover, there are numerous possible reasons for why change may be opposed: misunderstandings about the need for change, fear of failure, fear of loss of professional autonomy, fear of additional workload, fear of transparency, reluctance to share instrumentation [8], concerns about confidentiality, concerns about the impact on human 
resources and the professional demands that come with such a change. In addition, the ICT professionals need to have a grasp of what is actually happening and needed in care practice.

With all this in mind, caregivers will not necessarily accept a (new) health information system and use it in daily practice $[16,44]$. Information technology that is not used, or is only partly used, cannot reasonably be expected to contribute to improving the quality of care. On the contrary, it can be an extra burden or cause other problems [45]. It is clear that the impact of such a change could be a contributing factor leading to an organisational crisis, causing conflict among professional groups. It is therefore crucial to understand how aspects of real-world activities relate to one another [41] and to clarify what the influencing factors are of the acceptance of and the use or failure of the information system.

In this paper we explore the applicability of the unified theory of acceptance and use of technology (UTAUT) theoretical model in the BelRAI healthcare project in analysing the acceptance of the BelRAI web application by healthcare professionals in three Belgian care settings (home care, nursing home care and acute hospital care for older people with disabilities). This will help to broaden our understanding of the development and implementation of healthcare information systems.

\section{The unified theory of acceptance and use of technology}

Information technologies permeate all aspects of human life and today's organisations, having an increasing importance [46]. With respect to understanding individual acceptance of new information technologies or systems, it is not surprising that prior research was mainly focused on sociological and psychological factors [45-48]. Understanding and clarifying the drivers influencing the acceptance and the use or failure of information systems (IS) has always been a long-term issue in technology and IS research [49]. To promote a unified view of user acceptance and in an effort to identify the most significant influences, Venkatesh et al. [46] reviewed and compared the following behavioural models (evolved models not included): social cognitive theory (SCT) [50], theory of reasoned action (TRA) [51], theory of planned behaviour (TPB) [52,53], model of PC utilization (MPCU) [54], technology acceptance model (TAM) [49], combined TAM and TPB (C-TAM-TPB) [55], innovation diffusion theory (IDT) [56] and motivational model (MM) [57]. Each of these models has the intention to use technology or the actual use of technology as the dependent variable whereby the variance in user intentions is explained between $17 \%$ and $53 \%$ [46].

By integrating the conceptual and empirical similarities of these eight models, UTAUT explains up to $70 \%$ of the variance in intention to use technology and about $50 \%$ of the variance in technology use [46]. This makes UTAUT an interesting starting point from which to understand technology or system acceptance.

According to Venkatesh et al. [46], UTAUT (Figure 1) includes three direct determinants of behavioural intention to use a system:

- performance expectancy (PE) defined as the degree to which an individual believes that using the system will help him or her to achieve increases in job performance. Performance expectancy proves to be a significant determinant of behavioural intention, moderated by gender and age such that the effect is strongest for younger men;

- effort expectancy (EE) defined as the degree of ease associated with the use of the system. It was found that the effect of effort expectancy on behavioural intention is moderated by gender and age such that the effect is strongest for older women in the early stages of experience with the system;

- social influence (SI) defined as the degree to which an individual perceives that important others believe he or she should use the new system. It was found that the effect of social influence on behavioural intention is moderated by gender, age, experience and voluntariness such that the effect is strongest for older women in early stages of experience in mandatory contexts.

UTAUT contains also two direct determinants of use behaviour:

- facilitating conditions (FC) defined as the degree to which an individual believes that an organisational and a technical infrastructure exists to support use of the system. It was found that the effect of facilitating conditions on use behaviour or system use is moderated by age and experience such that the effect is strongest for older workers in later stages of experience;

- behavioural intention (BI) is not defined explicitly but consistent with the underlying theory for all of the intention models, Venkatesh et al. [46] have found that behavioural intention has a significant positive influence on use behaviour or system use. They state: 'The role of intention as a predictor of behaviour (e.g., usage) is critical and has been wellestablished in IS and the reference disciplines.'

Finally, Venkatesh et al. [46] describe four moderators that would influence the effect of the determinants on behavioural intention and/or use behaviour: gender, age, experience with the system and voluntariness of use. 


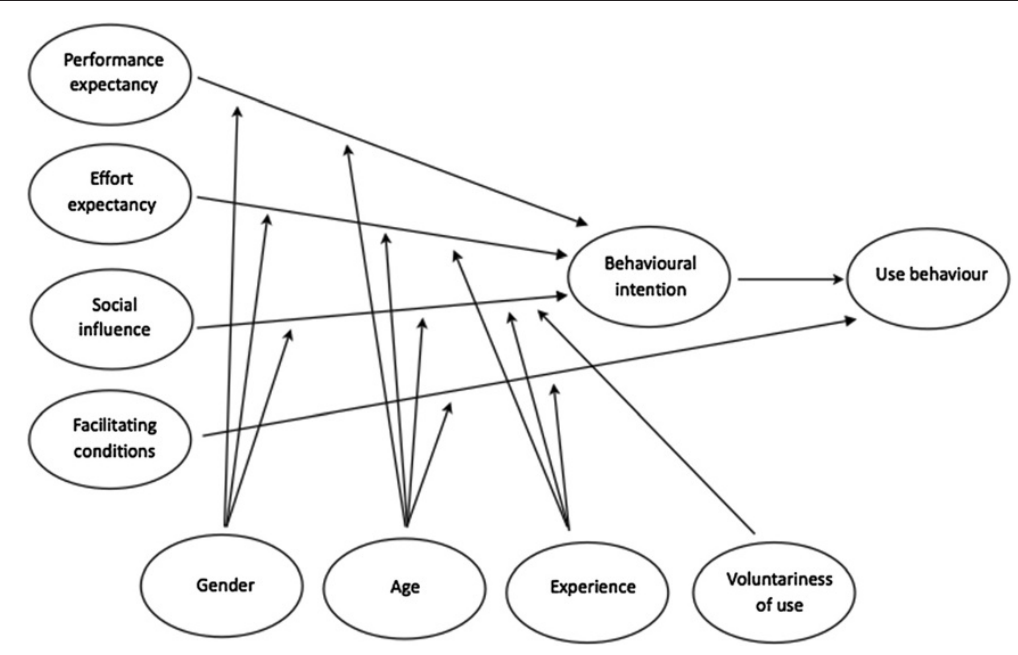

Figure 1 Original UTAUT model [46].

\section{Methods}

\section{Research model and hypotheses}

UTAUT was originally developed outside of the healthcare context. We built upon this framework to complement prior research on technology acceptance and use $[45,48,58,59]$ by exploring the applicability of the UTAUT model in the context of the BelRAI healthcare project. The study has the following characteristics.

Firstly, as there are no reliable indicators available on actual use of the BelRAI web application (e.g., archival system logs providing information on duration of use, number of features used, frequency of use of each feature, ...), the emphasis of the study is on understanding which determinants influence behavioural intention to use the system. Consequently, we could not test the influence of facilitating conditions on actual usage.

Secondly, organisational contexts can increase or decrease the variation in phenomena and result in relationships fluctuating from stronger to weaker, positive to negative, significant to non-significant $[60,61]$. Consistent with this, healthcare professionals might respond differently than people in other types of organisations.

Previous research in different healthcare settings [45,62-64] mentioned that performance expectancy or related constructs strongly influence behavioural intention. The uptake of technologies that was perceived as advantageous (financially, or with respect to time-saving and greater job satisfaction) was more straightforward for clinicians, nurses or other healthcare professionals. Following this logic, we believe that performance expectancy will have an influence on behavioural intention in this study context (H1, Table 1).

Wills et al. [45] and de Veer et al. [63] found that an easy-to-use technology enhanced the uptake of a new system among caregivers. Hence, we expect that effort expectancy will have an influence on behavioural intention (H2).

Consistent with Venkatesh et al. [46], Wills et al. [45] found that social influence constructs also became significant in mandatory healthcare settings particularly among women in early stages of experience. This research is conducted in a mandatory setting with mostly female caregivers. We suggest that social influence will have an impact on behavioural intention (H3).

De Veer et al. [63] suggested that the acceptance of a new technology by nurses was influenced by facilitating characteristics. Chau et al. [64] found that constructs related to facilitating conditions influenced behavioural intention in healthcare settings. Therefore, we have reason to suspect that facilitating conditions will have an influence on behavioural intention to use the BelRAI web application (H4).

Anxiety (ANX), self-efficacy (SE) and attitude towards using technology (ATUT) are determinants in their

\section{Table 1 Hypotheses}

H1 Performance expectancy will influence behavioural intention to use BelRAl.

$\mathrm{H} 2$

Effort expectancy will influence behavioural intention to use BelRAl.

H3 Social influence will influence behavioural intention to use BelRAl.

H4

Facilitating conditions will influence behavioural intention to use BelRAI.

H5

Anxiety will influence behavioural intention to use BelRAl.

H6

Self-efficacy will influence behavioural intention to use BelRAl.

H7 Attitude towards using technology will influence behavioural intention to use BelRAI. 
original models. Based on SCT, anxiety is defined as evoking anxious or emotional reactions when it comes to using a system, and self-efficacy is defined as judgement of one's own ability to use a system. Based on TRA, ATUT is defined as an individual's overall affective reaction to using a system. Having no direct effect on behavioural intention, ANX, SE and ATUT were dropped in Venkatesh's study [46]. However, we thought it would be valuable to reexamine the influence of these constructs on behavioural intention in the BelRAI healthcare setting ( $\mathrm{H} 5, \mathrm{H} 6, \mathrm{H} 7)$.

Thirdly, as we have not examined the potential moderating roles of age, gender, experience with the system and voluntariness, we have restricted our study to direct effects only. Moreover, Venkatesh et al. [58] found that a more parsimonious version of UTAUT, with only age as a moderator, performs better in explaining behavioural intention among doctors in a hospital setting.

\section{Settings and context}

The study focuses on data derived from the BelRAI feasibility project integrating home care (interRAI home care assessment instrument [65]), residential or nursing home care (interRAI long-term care facility assessment instrument [66]) and acute hospital care (interRAI acute care assessment instrument [67]) for (frail) older people [68]. We have also included data of a study about the effects of innovative home care projects (alternatives or add-ons to the standard home care services) in Flanders (Belgium) using the interRAI home care assessment instrument [69].

\section{Participants}

The participants are a heterogeneous group of Flemish licensed or qualified caregivers (nurses, physical therapists, occupational therapists, speech-language therapists, dieticians, podiatrists, social workers, physicians, psychologists, dentists, pharmacists). They were all using the BelRAI web application for interRAI assessments for the duration of the project in their own (home, residential or acute hospital) care setting on a mandatory basis. All the participants attended training sessions customised to their specific needs and all persons who followed a training session were asked to participate in this study.

\section{Questionnaire}

A Flemish-Dutch translation of a structured questionnaire for data collection was used, containing items based on constructs validated in the original UTAUT study [46]. Results from an earlier study have shown that the UTAUT tool is 'robust enough to withstand translation and to be used cross-culturally, outside its original country and language of origin' [70]. The original English version of the UTAUT tool was translated independently into a
Flemish-Dutch (official language of the Northern region of Belgium) version by a qualified (licensed) translator on an item-by-item basis using the back-translation process. Thereafter, two bilingual speakers carefully reviewed the translation ensuring that meaning and nuance were not lost and remained as true to the original as possible [71]. Changes only relate to the name of the system used.

The questionnaire items related to the UTAUT constructs $^{\mathrm{b}}$ were measured by means of a 1 to 7 -point Likert agreement scale ranging from "Strongly disagree" to "Strongly agree". Effort expectancy is reverse coded so that high effort expectancy suggests high ease of use [46].

In the questionnaire additional information such as age and gender was also collected.

\section{Data collection}

The questionnaire and a cover letter were designed using QuestionPro [72] and made available to the participants on the web at one point in time. The participants were invited by email. To maximise the response rate and reduce non-response, non-responders were sent a reminder requesting participation one week after the initial-mail-out and again after three weeks [73].

\section{Ethical considerations}

As this study occurred without patient involvement, no approval by an ethics committee was required in Belgium. Participants were assured response anonymity.

\section{Data analysis}

Theoretical concepts such as attitudes, intentions and preferences, also known as latent variables, factors or constructs, cannot be observed or measured directly [74,75]. Constructs are measured indirectly through indicators (observable, measurable or manifest variables such as an item on a questionnaire) designed to elicit responses related to a construct [76]. Scaling techniques have been developed to study the complexity inside a system and to derive information on constructs from indicators. However, to overcome limitations of the first generation regression-based approaches, more and more researchers started using structural equation modelling (SEM) as an alternative [77].

In this study, data analysis was done using SEM. SEM is a multivariate technique combining aspects of multiple regression and factor analysis and thus testing underlying factors and hypotheses simultaneously in the same analysis [76,78]. In an SEM analysis researchers estimate a causality network according to a theoretical model, linking multiple dependent or independent constructs, each measured through a number of indicators, testing theory with empirical data [79]. More specifically, there are two approaches, the covariance-based (e.g. linear structural relations a.k.a. LISREL being the most 
popular one among social science researchers) and the variance-based or components-based approach (e.g. partial least squares a.k.a. PLS being widely used in performing information systems research) $[45,46,48,58,59,76,77,80]$. Covariance-based SEM examines all possible specified and unspecified covariances in the model. PLS only examines the explicitly stated covariances in the model [76] and focuses on maximising the variance of the dependent variables which are explained by the independent ones [77].

The PLS path modelling approach was reported in the original UTAUT study [46] as having minimal demands on sample size, measurement scales and residual or underlying data distributions $[81,82]$.

Like any SEM, PLS refers to two inter-related models [76,78]: a measurement or outer model describing the constructs (latent variables) that make up the model and the relationships between the constructs and their indicators (manifest variables) and a structural or inner model describing the causal relationships among these constructs $[74,79]$.

Specifically, for PLS, the generated weights and loadings are outer model parameter estimates, while the path coefficients are inner model parameter estimates.

To evaluate the measurement model, PLS performs a confirmatory factor analysis (CFA) by testing the mandatory [75] reliability and construct validity (factorial validity of the constructs). Reliability relates to the measurement within constructs and is thus independent of the status within other constructs; construct validity relates to the measurement between constructs $[75,80]$.

The evaluation of the internal consistency of constructs (ICR) (e.g. Cronbach's alpha (CA) to test the unidimensionality of a set of questionnaire items measuring the extent to which all the variables are related to each other) is one technique to assess reliability. Moreover, PLS analysis provides other coefficients attesting to the reliability of the survey instrument such as composite reliability (CR) and average variance extracted (AVE) for each construct. As a rule of thumb the cut-off for (CA) is $0.70[83,84]$. The recommended respective thresholds for CR and AVE are 0.70 and 0.50 [85].

To establish construct validity [75], PLS examines convergent and discriminant validity of the scale estimating how well a variable measures what it is intended to measure [45] or how well the measurement items relate to the constructs [80].

Convergent validity is established when each measurement item of the model loads with a t-value above 1.96 (rejecting the null hypothesis of no effect) on its latent construct meaning that each measurement item correlates strongly with its theoretical pre-specified construct. The $\mathrm{p}$-value of this t-value should be significant at least at the 0.05 alpha protection level [80].
Discriminant validity is established under two conditions: 1) the correlation of the latent variable scores with the measurement items needs to show an appropriate pattern of loadings, one in which the measurement items load highly $(>0.70)$ on their theoretically assigned construct and weakly $(<0.30)$ on other constructs (cross loadings); 2) establishing discriminant validity in PLS also requires an appropriate AVE analysis [75,80]. With the latest version of PLS-Graph 03.00 build 1126 of 2003, AVEs are generated automatically using bootstrapping as a resampling procedure. The AVE measures the variance captured by a latent construct being the shared (or explained) variance. The square root of AVE of each construct should be much larger than its variance shared with any of the other constructs in the model and should be at least 0.50 . Conceptually, it is equivalent to saying that the correlation between the construct and its measurement items should be larger than its correlation with the other constructs $[45,76,80]$.

Having established reliability, convergent and discriminant validity of the constructs, the next step is to test the structural model for the hypothesised paths. To evaluate the structural model, PLS estimates path coefficients for each hypothesised path using bootstrapping, a nonparametric technique for assessing the precision of the PLS estimates $[81,86]$. The corresponding t-values suggest significance of the coefficients ( $t$-values $>1.96$, significance level $\mathrm{p}<0.05$ ) [80]. To ascertain how well the model fits the hypothesised relationship, PLS generates the square of the correlation coefficient $\left(R^{2}\right)$ for each dependent construct in the model. Similar to regression analysis, $\mathrm{R}^{2}$ is interpreted as the percentage of shared (or explained) variance and thus represents the proportion of variance in the dependent constructs which can be explained by the independent ones $[45,77]$.

We ran PLS-Graph (c), a software package which applies PLS $[74,81,86]$ for SEM. Statistical analysis system (SAS) 9.3 C was used for descriptive analysis and creation of PLS-Graph data files.

\section{Results}

\section{Sample characteristics}

Of the 661 invitations to take part in the study, 601 questionnaires were viewed by the persons invited and 421 were started. 282 respondents fully completed the questionnaire. 216 of them (76.60\%) were female. 69 (24.47\%) were between the ages of 20-29, 85 (30.14\%) between 3039,68 (24.11\%) between 40-49 and 60 (21.28\%) were older than $50.80 .14 \%$ of the participants had been using the new BelRAI application for more than 4 months; $70.21 \%$ had been using the technology for more than 7 months.

With PLS we performed a complete case analysis using data of 282 questionnaires. 


\section{The measurement model}

To evaluate the measurement model, PLS tests the reliability and the construct validity. Reliability relates to the measurement within constructs. Construct validity relates to the measurement between constructs $[75,80]$.

As in the original study of Venkatesh et al. [46], for practical analytical reasons the constructs were operationalised by using the highest-loading items ${ }^{\mathrm{c}}$ from each of the respective scales (Table 2). Given this specific healthcare situation, these items did not always accord with the highest-loading items used to measure the core constructs in the original UTAUT: only the items with an asterisk were selected for inclusion in the final UTAUT model in the study of Venkatesh et al. [46].

Table 3 summarizes the results for the items comprising our model. As an evaluation of the internal consistency reliability (ICR) of each construct, the values for Cronbach's alpha (CA) exceed 0.70 the minimal cut-off as

Table 2 The measurement model: individual loadings of the highest-loading items in this study

\begin{tabular}{|c|c|c|c|}
\hline Construct & Individual item & Measure & $\begin{array}{l}\text { PLS item loading } \\
(\mathrm{N}=282)\end{array}$ \\
\hline \multirow[t]{5}{*}{ PE } & U5 & Using BelRAI makes it easier to do my job. & 0.9384 \\
\hline & RA2 & Using BelRAI improves the quality of the work I do. & 0.9604 \\
\hline & RA3 & Using BelRAI makes it easier to do my job. & 0.9618 \\
\hline & RA4 & Using BeIRAI enhances my effectiveness on the job. & 0.9700 \\
\hline & RA5* & Using BelRAl increases my productivity. & 0.9506 \\
\hline \multirow[t]{4}{*}{ EE } & EOU1 & Learning to operate BeIRAl is easy for me. & 0.9090 \\
\hline & $\mathrm{EOU}^{*}$ & My interaction with BelRAI is clear and understandable. & 0.8965 \\
\hline & EOU5* & It is easy for me to become skilful at using BeIRAI. & 0.9074 \\
\hline & EOU6* & I find BelRAl easy to use. & 0.8782 \\
\hline \multirow[t]{4}{*}{ ATUT } & A3 & I like the idea of using BeIRAI. & 0.9174 \\
\hline & IM3 & I have fun using BelRAI. & 0.9600 \\
\hline & $\mathrm{AF} 2^{*}$ & Working with BelRAI is fun. & 0.9351 \\
\hline & Affect $1^{*}$ & I like working with BelRAI. & 0.9447 \\
\hline \multirow[t]{3}{*}{ SI } & $\mathrm{SF} 2^{*}$ & The senior management of this organisation has been helpful in the use of BelRAI. & 0.7663 \\
\hline & SF3 & My supervisor is very supportive of the use of BelRAI for my job. & 0.9298 \\
\hline & SF4* & In general, the organisation has supported the use of BelRAI. & 0.9439 \\
\hline \multirow[t]{4}{*}{ FC } & $\mathrm{PBC} 1$ & I have control over using BelRAl. & 0.9276 \\
\hline & $\mathrm{PBC} 2^{*}$ & I have the resources necessary to use BelRAl. & 0.8756 \\
\hline & PBC $3^{*}$ & I have the knowledge necessary to use BelRAI. & 0.9049 \\
\hline & PBC4 & Given the resources, opportunities and knowledge it takes to use BelRAl, it is easy for me to use BelRAI. & 0.8203 \\
\hline \multirow[t]{4}{*}{ SE } & SE4* & $\begin{array}{l}\text { Using BelRAI, I could complete the job or task if I had seen someone else using it } \\
\text { before trying it myself. }\end{array}$ & 0.7972 \\
\hline & SE5 & Using BeIRAI, I could complete the job or task if I could call someone for help if I got stuck. & 0.8373 \\
\hline & SE6* & Using BelRAI, I could complete the job or task if someone else had helped me get started. & 0.8448 \\
\hline & SE9 & Using BelRAI, I could complete the job or task if someone showed me how to use it first. & 0.8586 \\
\hline \multirow[t]{4}{*}{ ANX } & ANX $1^{*}$ & I feel apprehensive about using BelRAI. & 0.9315 \\
\hline & ANX2* & It scares me to think that I could lose a lot of information using BelRAI by hitting the wrong key. & 0.8081 \\
\hline & ANX3* & I hesitate to use BelRAI for fear of making mistakes I cannot correct. & 0.8046 \\
\hline & ANX4* & BelRAI is somewhat intimidating to me. & 0.8054 \\
\hline \multirow[t]{3}{*}{$\mathrm{BI}$} & $\mathrm{B} \mid 1^{*}$ & I intend to use BelRAI in the next 3 months. & 0.9776 \\
\hline & $\mathrm{B} \mid 2^{*}$ & I predict I would use BeIRAI in the next 3 months. & 0.9708 \\
\hline & $\mathrm{BI} 3^{*}$ & I plan to use BelRAI in the next 3 months. & 0.9614 \\
\hline
\end{tabular}

PE: Performance expectancy; EE: Effort expectancy; ATUT: Attitude towards using technology; SI: Social influence; FC: Facilitating conditions; SE: Self-efficacy; ANX: Anxiety; BI: Behavioural intention.

All questionnaire items were measured using a 7-point Likert agreement scale ranging from "Strongly disagree" to "Strongly agree". All constructs were modelled using reflective indicators. The items with an asterisk were selected for inclusion in the final UTAUT model in the study of Venkatesh et al. [46]. We refer to the same study for an explanation with regard to the abbreviations and the non-relevant items. 
Table 3 The measurement model: reliability results

\begin{tabular}{llllll}
\hline Construct & Mean & Std dev & Cronbach's alpha & Construct CR & Construct AVE \\
\hline PE & 3.4 & 1.4 & 0.98 & 0.982 & 0.915 \\
EE & 4.1 & 1.3 & 0.92 & 0.943 & 0.806 \\
ATUT & 3.6 & 1.4 & 0.96 & 0.968 & 0.883 \\
SI & 4.4 & 1.3 & 0.86 & 0.914 & 0.781 \\
FC & 4.6 & 1.4 & 0.91 & 0.934 & 0.780 \\
SE & 4.8 & 1.0 & 0.86 & 0.902 & 0.697 \\
ANX & 2.5 & 1.2 & 0.88 & 0.905 & 0.704 \\
BI & 5.0 & 1.7 & 0.97 & 0.979 & 0.941 \\
\hline
\end{tabular}

In accordance with the study of Venkatesh et al. [46] we operationalised the constructs in our UTAUT model by using the highest-loading items from each of the respective scales.

Std Dev: Standard deviation; CR: Composite reliability; AVE: Average variance extracted.

recommended by Nunnally [83] and Nunnally et al. [84]. PLS analysis also provides average variance extracted (AVE) and composite reliability (CR). For each construct, AVE exceeds 0.50 and $C R$ exceeds 0.70 , which are the recommended thresholds by Fornell et al. [85]. These values denote adequate reliability of the survey instrument.

To establish construct validity, PLS examines convergent and discriminant validity of the scale. In this study, each measurement item of the model loads with a t-value above 1.96 on its latent construct. This indicates that each measurement item correlates strongly with its theoretical pre-specified construct. The $\mathrm{p}$-values of the $\mathrm{t}$-values are all significant at the 0.001 alpha protection level, so convergent validity is confirmed ${ }^{\mathrm{d}}$. Discriminant validity is established because: 1) the correlation of the latent variable scores with the measurement items shows an appropriate pattern of loadings; the measurement items have high loadings (>0.70) on their theoretically assigned construct and low loadings $(<0.30)$ on other constructs. However, the items of the attitude towards using technology construct cross-loaded on PE; 2) the square root of $\mathrm{AVE}^{\mathrm{e}}$ of each construct (represented by the diagonal values in bold) is significantly higher than the correlations between constructs (represented by the off-diagonal values) in the adjoining columns and rows of Table 4.

\section{The structural model}

To test the structural model, PLS estimates path coefficients for each hypothesised path using bootstrapping (100 samples). Path coefficients for each hypothesised path are shown in Table 5 together with the corresponding t-values.

Facilitating conditions proved to have the most significant influence on behavioural intention to use BelRAI, followed by self-efficacy. The other constructs have no significant influence on behavioural intention.

Hypothesis 1 is not supported since performance expectancy or the degree to which an individual believes that using the system will help him or her to achieve increases in job performance has no significant influence on behavioural intention $(\mathrm{t}$-value $=0.3947$, $\mathrm{p}$-value $=0.69$ ).

In the same manner, hypothesis 2 is not supported since neither effort expectancy nor the degree of ease associated with the use of the system has a significant relationship with behavioural intention ( $\mathrm{t}$-value $=0.0131$, $\mathrm{p}$-value $=0.99$ ).

In parallel with this there is no significant connection between social influence (the degree to which an individual perceives that important others believe he or she should use the new system) and behavioural intention ( $\mathrm{t}$-value $>1.8268, \mathrm{p}$-value $=0.07)$ hence not consistent with hypothesis 3.

In accordance with hypothesis 4 , facilitating conditions (the degree to which an individual believes that an organisational and a technical infrastructure exists to support use) have a positive effect on behavioural intention to use BelRAI ( $\mathrm{t}$-value $=3.6666$, $\mathrm{p}$-value $=0.00$ ). This is in contrast with the findings of Venkatesh et al. [46]. They state that facilitating conditions have no significant influence on behavioural intention in the presence of effort expectancy.

Hypothesis 5 is not supported since anxiety described as evoking anxious or emotional reactions when it comes to using a system has no significant influence on behavioural intention ( $\mathrm{t}$-value $=1.3671, \mathrm{p}$-value $=0.17$ ). This affirms the removal of anxiety from the final UTAUT model [46].

Self-efficacy or the judgement of one's ability to use a system has a positive effect on behavioural intention $(\mathrm{t}$-value $=3.1904, \mathrm{p}$-value $=0.00)$, hence hypothesis 6 is supported. This is all the more noteworthy since selfefficacy was dropped from the final UTAUT model in the original study [46].

Finally, hypothesis 7 is not supported since attitude towards using new technology defined as an individual's overall affective reaction to using a system has no significant influence on behavioural intention ( $\mathrm{t}$-value $=1.4945$, $\mathrm{p}$-value $=0.14$ ). This affirms the removal of attitude from the final UTAUT model [46].

To ascertain how well the model fits the hypothesised relationship, PLS generates the square of the correlation 
Table 4 The measurement model: inter-construct correlation matrix with square root of AVE of each construct

\begin{tabular}{|c|c|c|c|c|c|c|c|c|}
\hline & $\mathrm{PE}$ & $\mathrm{EE}$ & ATUT & SI & FC & SE & ANX & $\mathrm{BI}$ \\
\hline$\overline{\mathrm{PE}}$ & 0.957 & & & & & & & \\
\hline $\mathrm{EE}$ & 0.499 & 0.898 & & & & & & \\
\hline ATUT & 0.795 & 0.536 & 0.940 & & & & & \\
\hline SI & 0.280 & 0.394 & 0.314 & 0.778 & & & & \\
\hline FC & 0.160 & 0.606 & 0.240 & 0.495 & 0.883 & & & \\
\hline SE & 0.033 & 0.272 & 0.169 & 0.215 & 0.276 & 0.835 & & \\
\hline ANX & -0.189 & -0.387 & -0.256 & -0.201 & -0.390 & -0.203 & 0.839 & \\
\hline $\mathrm{BI}$ & 0.165 & 0.361 & 0.261 & 0.368 & 0.466 & 0.361 & -0.277 & 0.970 \\
\hline
\end{tabular}

Off-diagonal values represent correlations between constructs.

Diagonal values (bold) are the square root of AVE of each construct.

Discriminant validity is confirmed if diagonal values are significantly higher than off-diagonal values.

coefficient $\left(\mathrm{R}^{2}\right)$ for the dependent variable behavioural intention in the model. The $\mathrm{R}^{2}$ value for behavioural intention (0.308) indicates that the 'direct effects only' model explains $30.8 \%$ of the variance in behavioural intention to use BelRAI (Figure 2).

\section{Discussion}

This paper describes a study concerning the utilisation of the UTAUT model to provide an explanation on professional caregivers' acceptance of the BelRAI web application. Given the fact that UTAUT was originally developed outside the healthcare context, we built upon this framework to complement prior related research on technology acceptance and use $[45,48,58,59]$ by exploring the applicability of the UTAUT model in the specific BelRAI healthcare project - home care, residential care and acute hospital care for older and disabled people.

This study shows that performance expectancy, effort expectancy and social influence do not have a significant influence on behavioural intention as shown in the original UTAUT study [46] and other related research on technology acceptance and use $[45,48,58,59]$. However, behavioural intention is influenced by facilitating conditions associated with the presence of the resources and the knowledge required to use the system, the degree of compatibility of the new system with other systems in use and the availability of assistance in the case of system difficulties. Similarly, self-efficacy associated with the possibility to complete a task using the new information system with only the built-in help facility, having the possibility to call someone for help and having enough time to practice, has a significant influence on behavioural intention to use the BelRAI web application.

These results seem to be in line with the findings by Declercq et al. [68]. Inadequate computer equipment (hardware, software, internet connection) causes frustration among users, is counterproductive, and constitutes significant barriers to accepting the new technology. At the same time it is important to achieve the right balance between confidentiality and accessibility. The BelRAI web application meets the requirements set by the Belgian Commission for the Protection of Privacy, and the privacy and security standards have been positively evaluated by the users. However, rigid security regulations also result in access procedures that are complex and time-consuming, as a result of which they negatively influence the application's user-friendliness. Occasionally, when it is possible to get around the security measures (by exchanging the eIDs, for instance), a result will be reached that is opposite to the one intended.

In any case, there is need for high quality education, both internally and externally. The expectations for external education and support can strongly depend on the context or setting. In one setting there might be a need for practical education, whereas in another a rather theoretical training might be appropriate. In an initial phase the training can be organised per setting, so that each setting gets specific information based on its needs. During a subsequent phase, the training groups can be composed rather heterogeneously in order to put an emphasis on the interaction and collaboration between different settings. This is particularly appreciated by home care caregivers

Table 5 The structural model: path coefficients, t-values and $p$-values

\begin{tabular}{lllllllll}
\hline & PE & EE & ATUT* & SI & FC & SE* $^{*}$ & ANX* & BI \\
\hline Path coefficient & -0.0390 & -0.0010 & 0.1260 & 0.1370 & $\mathbf{0 . 2 8 7 0}$ & $\mathbf{0 . 2 1 8 0}$ & -0.0690 & 0.0000 \\
t-value & 0.3947 & 0.0131 & 1.4945 & 1.8268 & $\mathbf{3 . 6 6 6 6}$ & $\mathbf{3 . 1 9 0 4}$ & 1.3671 & 0.000 \\
p-value & 0.69 & 0.99 & 0.14 & 0.07 & $\mathbf{0 . 0 0}$ & $\mathbf{0 . 0 0}$ & 0.17 & 1.00 \\
\hline
\end{tabular}

Constructs with an asterisk were dropped from the final UTAUT model in the study of Venkatesh et al. [46]. 


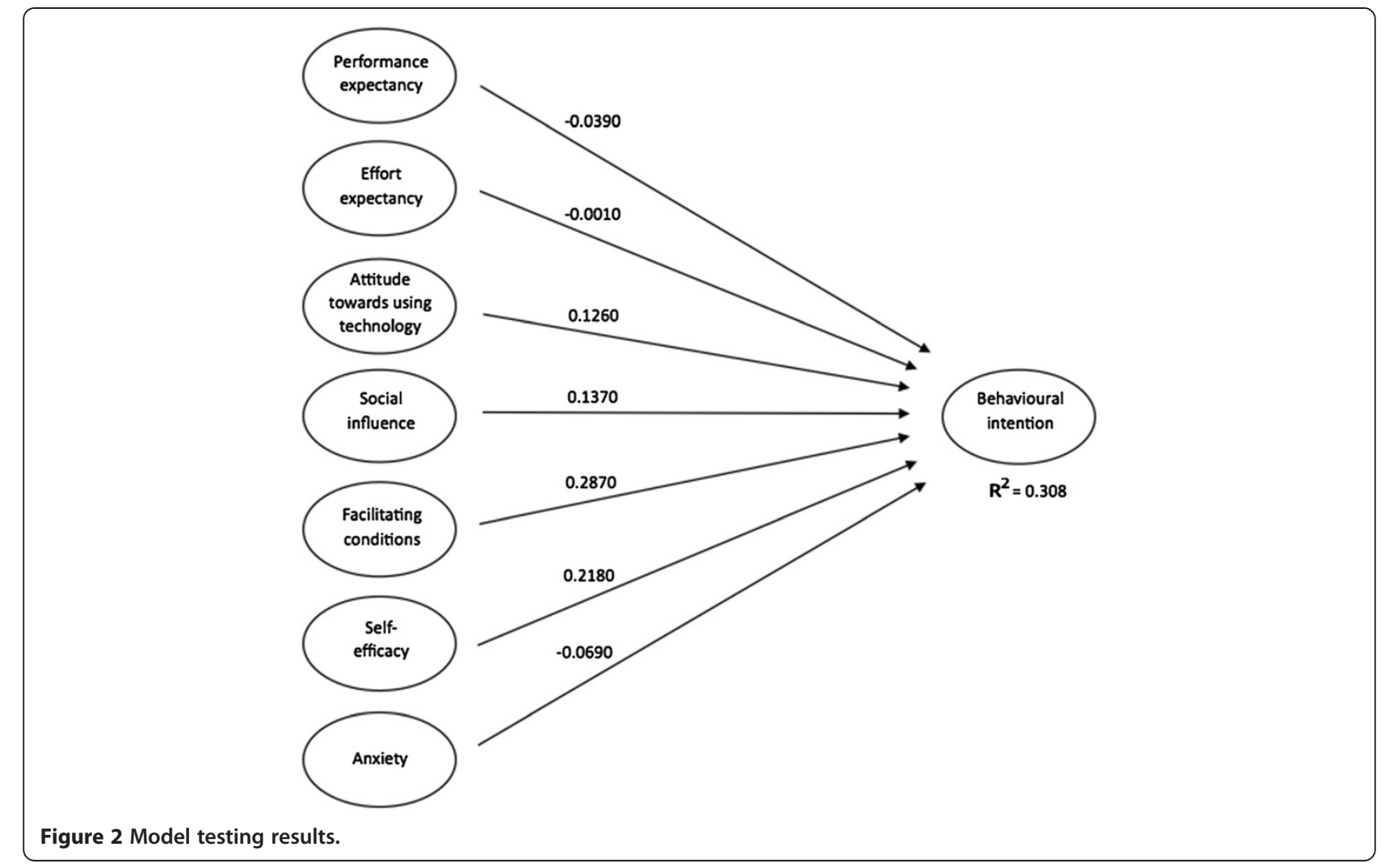

since they hardly get in touch with other caregivers active in both home care and other care settings. Also, the periods in between different training phases should be long enough in order to enable caregivers to acquire experience and give feedback. The group sizes and the number of teachers must be in tune with one another so that teachers can adopt a problem-solving approach. The internal training sessions, organised by the organisations themselves, should be very practical. For an organisation, it is appropriate to appoint a reference person who can hold the position of internal trainer and act as a contact person. Assigning some staff members to work on the project can facilitate a full-time follow-up and implementation. The learning period does not end after the final training session. In order to be able to fluently use new technological tools, each caregiver should pass through a post-training learning process. Moreover, each caregiver should be given the opportunity to gain sufficient experience in a variety of situations. In addition to the technological aspect, the content (assessment) as such constitutes an indispensable part of the learning process. Frequent and intensive exercises are required in order to have good command of all applications. However, frequent staff changes can seriously disturb the learning process.

Time is an important resource. In practice, a high workload, a lack of personnel, high client turnover, and the presence of acute problems (acute hospitals) turn out to be significant barriers standing in the way of implementing new information technology. In order to improve efficiency and avoid an increased workload, the degree of integration of existing information technology (e.g., electronic patient records) with new technologies is decisive in the success of implementation. It is in everyone's interest that everything can happen in a user-friendly and safe way, without technical failures and with a minimum of intermediate steps. Integrated technology leads to fewer difficulties and will be accepted and used more rapidly.

During the implementation of new technologies, it is also important for active caregivers not to feel alone, but rather to feel supported in times of doubt by the care team, the (middle) management and other caregivers involved. Other factors that can contribute to a successful implementation are a help desk, a wiki website, and the possibility of being able to work in a quiet environment. Moreover, the collaboration process can be influenced by the physical proximity of various disciplines: people working within the same organisation collaborate more easily than people employed at different sites.

Although the use of the BelRAI application was mandatory, it is plausible that the behavioural intention of professionals is influenced by the short-term nature of this project. Simulating mandatory use of new information technology in a public healthcare setting is not straightforward. Therefore, since the future professional 
value of BelRAI is not guaranteed, performance expectancy may not have influenced behavioural intention. Similarly, effort expectancy may not have a significant relationship with behavioural intention because people tend not to exert great effort during a pilot project. Social influence may not have an impact on behavioural intention because of a difference in attitude between caregivers and typical technology users. Future study designs should disentangle these effects inside the UTAUT framework to understand user acceptance in the context of a permanent implementation. The measurement of behavioural intention to use new information technology could be expanded to take into account the emotional disposition of professional caregivers. Ultimately, when new information technology is implemented on a large scale, professionals should be looking forward to using it.

\section{Conclusions}

The practical implications of this research are that goodquality software, interoperability and compatibility with other information systems, easy access to computers, a degree of computer literacy, training facilities, built-in and online help and ongoing IT support are critical influencing factors in stimulating the behavioural intention to use new technology. These findings can be used by policy makers to maximise the acceptance and the success of new technology initiatives.

For researchers, this study indicates that a bottom-up approach should be preferred when building upon the UTAUT model. The conclusions of the original UTAUT study [46] with regards to the item and scale construction should not be copied blindly across different information systems. In the specific context of BelRAI, self-efficacy is an important influencing factor of behavioural intention while this factor is not retained in the original study.

Our elaboration of the UTAUT model is limited since no information is available about the actual use of the BelRAI web application. Other research should encompass variables that relate to actual use (e.g. frequency and duration) in order to investigate the influence of behavioural intention. In this research it is not possible to gain insight into non-response bias and to know who is cooperative and who is not. It is likely that respondents who did not complete the survey have a more negative attitude towards new technology. Future research should provide insight into the characteristics of the entire study population. Future research should also take into account experience with the system in a longitudinal evaluation and examine the effects of age, gender, healthcare context, profession, computer literacy and specific training sessions not only related to behavioural intention but also to actual usage of the system. To better understand healthcare professionals' acceptance of BelRAI, more research is needed to generalise the findings of this feasibility project to a future, broad implementation.

\section{Endnotes}

${ }^{a}$ Since 2006, different government-funded feasibility studies concerning the implementation of interRAI assessment instruments at a national level were carried out by an interuniversity team of the KU Leuven (Elderly Care Research Unit at LUCAS\& Center for Health Services and Nursing Research) and the Université de Liège (Département des Sciences de la Santé Publique) [68,87-91].

${ }^{\mathrm{b}} 85$ questionnaire items related to the UTAUT constructs were measured: Performance expectancy (PE), 24 items; Effort expectancy (EE), 10 items; Attitude towards using technology (ATUT), 14 items; Social influence (SI), 9 items; Facilitating conditions (FC), 11 items; Self-efficacy (SE), 10 items; Anxiety (ANX), 4 items; Behavioural intention (BI), 3 items.

${ }^{\mathrm{c}}$ Selection based on item loadings is consistent with recommendations in the psychometric literature [84]. "This approach favours building a homogenous instrument with high internal consistency but could sacrifice content validity by narrowing domain coverage" - items from some of the models not being represented in some of the core constructs [46].

${ }^{\mathrm{d}}$ The $\mathrm{p}$-value of this $\mathrm{t}$-value should be significant at the 0.05 alpha protection level [80].

${ }^{\mathrm{e}} \mathrm{By}$ the latest version of PLS-Graph 03.00 build 1126 of 2003 AVEs are generated automatically using bootstrapping as a resampling procedure. The AVE measures the variance captured by a latent construct being the shared (or explained) variance. The square root of AVE of each construct should be much larger than its variance shared with any of the other constructs in the model and should be at least 0.50 . Conceptually, it is equivalent to saying that the correlation between the construct and its measurement items should be larger than its correlation with the other constructs $[45,76,80]$.

${ }^{\mathrm{f}}$ The corresponding $\mathrm{t}$-values suggest significance of the coefficients ( $\mathrm{t}$-values $>1.96$, significance level $\mathrm{p}<0.05$ ) [80]. PLS generates the square of the correlation coefficient $\left(R^{2}\right)$ for each dependent construct in the model. $R^{2}$ is interpreted as the percentage of shared (or explained) variance and thus represents the proportion of variance in the dependent constructs which can be explained by the independent ones $[45,77]$.

\section{Abbreviations}

UTAUT: Unified theory of acceptance and use of technology; ICT: Information and communication technologies; IT: Information technology; IS: Information systems; SCT: Social cognitive theory; TRA: Theory of reasoned action; TPB: Theory of planned behaviour; MPCU: Model of PC utilization; TAM: Technology acceptance model; C-TAM-TPB: Combined TAM and TPB; IDT: Innovation diffusion theory; MM: Motivational model; PE: Performance expectancy; EE: Effort expectancy; SI: Social influence; FC: Facilitating 
conditions; BI: Behavioural intention; ANX: Anxiety; SE: Self-efficacy; ATUT: Attitude towards using technology; SEM: Structural equation modelling; LISREL: Linear structural relations; PLS: Partial least squares; SAS: Statistical analysis system; ICR: Internal consistency reliability; CA: Cronbach's alpha; AVE: Average variance extracted; CR: Composite reliability; Std Dev: Standard deviation.

\section{Competing interests}

The authors declare that they have no competing interests.

\section{Authors' contributions}

$V D, V B$ and $D A$ are involved in the study design and critically reviewed and approved the final manuscript. VD drafted the manuscript. All authors read and approved the final manuscript.

\section{Acknowledgements}

The authors gratefully acknowledge the contributions made by the caregivers and researchers participating in the BelRAI project and the innovative care projects in Belgium. We also acknowledge Prof. Dr. Viswanath Venkatesh for allowing us to use the UTAUT model and Prof. Dr. Wynne W. Chin for the PLS-Graph software. Special thanks go to Jurgen Berden, Bert Paepen and the Pyxima team for their extensive contributions to the development of the BeIRAl web application, to Johanna de Almeida Mello for her assistance with regard to the output algorithms and to Sarah Vanneste for translating and revising the questionnaire.

\section{Author details}

${ }^{1}$ Elderly Care Research Unit at LUCAS, KU Leuven, Kapucijnenvoer 39, 3000 Leuven, Belgium. ${ }^{2}$ Elderly Care Research Unit at LUCAS and Center for Sociological Research, KU Leuven, Kapucijnenvoer 39, 3000 Leuven, Belgium.

Received: 22 January 2013 Accepted: 15 November 2013

Published: 27 November 2013

\section{References}

1. Statistics Belgium. [http://statbel.fgov.be/nl/statistieken/cijfers/bevolking/ structuur/leeftijdgeslacht/belgie/]

2. Statistics Belgium. [http://statbel.fgov.be/nl/statistieken/cijfers/bevolking/ vooruitzichten/]

3. Kane RL, Kane RA: Assessment in long-term care. Annual Reviews Public Health 2000, 3:659-686.

4. Bergman H, Béland F, Karunananthan S, Hummel S, Hogan D, Wolfson C: Développement d'un cadre de travail pour comprendre et étudier la fragilité: pour l'initiative canadienne sur la fragilité et le vieillissement. Gerontol Soc 2004, 2(109):15-19.

5. Bergman H, Ferrucci L, Guralnik J, Hogan DB, Hummel S, Karunananthan S, Wolfson C: Frailty: an emerging research and clinical paradigm - issues and controversies. J Gerontol A Biol Sci Med Sci 2007, 62(7):731-737.

6. Bernabei R, Landi F, Onder G, Liperoti R, Gambassi G: Second and third generation assessment instruments: the birth of standardization in geriatric care. J Gerontol A Biol Sci Med Sci 2008, 63A(3):308-313.

7. Plsek PE, Greenhalgh $\mathrm{T}$ : Complexity science: the challenge of complexity in health care. Br Med J 2001, 323:625-628.

8. Gray LC, Berg K, Fries BE, Henrard J-C, Hirdes JP, Steel K, Morris JN: Sharing clinical information across care settings: the birth of an integrated assessment system. BMC Health Serv Res 2009, 9:71.

9. Coleman EA, Boult C: Improving the quality of transitional care for persons with complex care needs. J Am Geriatr Soc 2003, 51(4):556-557.

10. LaMantia MA, Scheunemann LP, Viera AJ, Busby-Whitehead J, Hanson LC: Interventions to improve transitional care between nursing homes and hospitals: a systematic review. J Am Geriatr Soc 2010, 58(4):777-782.

11. Coleman EA, Berenson RA: Lost in transition: challenges and opportunities for improving the quality of transitional care. Annals Internal Medicine 2004, 141(7):533-536.

12. Hirdes JP, Ljunggren G, Morris JN, Frijters DHM, Finne-Soveri H, Gray LC, Björkgren M, Gilgen R: Reliability of the interRAl suite of assessment instruments: a 12-country study of an integrated health information system. BMC Health Serv Res 2008, 8:277.

13. Hirdes JP, Fries BE, Morris JN, Steel K, Mor V, Frijters DHM: Integrated health information systems based on the RAI/MDS series of instruments. Healthc Manage Forum 1999, 12(4):30-40.
14. Wolfson M, Alvarez R: Towards integrated coherent health information systems for performance monitoring: the Canadian experience. In Measuring UP: improving health system performance in OECD Countries. Edited by Smith P. OECD Publications Service Paris France; 2012:133-155.

15. Leichsenring K: Integrated care for older people in Europe: latest trends and perceptions. Int J Integr Care 2012, 12:10-13.

16. Gaskin S, Georgiou A, Barton D, Westbrook J: Examining the role of information exchange in residential aged care work practices - a survey of residential aged care facilities. BMC Geriatr 2012, 12:40.

17. Communication from the Commission to the Council, the European Parliament, the European Economic and Social Committee and the Committee of the Regions. [http://eur-lex.europa.eu/smartapi/cgi/sga_doc? smartapi!celexplus!prod! DocNumber\&lg=en\&type_doc=COMfinal\&an_doc $=2004 \&$ nu_doc $=356]$

18. Implementing the Resident Assessment Instrument: Case studies of policymaking for long-term care in eight countries. [http://www.milbank. org/publications/milbank-reports]

19. Haux R, Ammenwerth $E$, Herzog W, Knaup P: Health care in the information society: a prognosis for the year 2013. Int J Med Inform 2002, 66:3-21.

20. Bayegan E: Knowledge representation for relevance ranking of patient-record contents in primary-care situations, PhD thesis. Norwegian University of Science and Technology, Department of Computer and Information Science; 2002.

21. interRAl. [http://www.interrai.org]

22. Dosa D, Bowers B, Gifford DR: Critical review of resident assessment protocols. J Am Geriatr Soc 2006, 54(4):659-666.

23. Carpenter Gl: Accuracy, validity and reliability in assessment and in evaluation of services for older people: the role of the interRAI MDS assessment system. Age Ageing 2006, 35(4):327-329.

24. Fries BE, Morris JN, Bernabei R, Finne-Soveri H, Hirdes JP: Rethinking the resident assessment protocols. J Am Geriatr Soc 2007, 55:1139-1140.

25. Onder G, Carpenter Gl, Finne-Soveri H, Gindin J, Frijters DHM, Henrard J-C, Nikolaus T, Topinkova E, Tosato M, Liperoti R, Landi F, Bernabei R: Assessment of nursing home residents in Europe: the services and health for elderly in long term care (SHELTER) study. BMC Health Serv Res 2012, 12:5.

26. Identifying and maintaining quality of long term care: an international case study of the interRAl assessment system for the OECD, Expert group meeting on long-term care. DELSA/HEA (2012)30. Paris; 2012.

27. Ikegami N, Igarashi C, Takagi Y, Kato T, Mor V: The impact of the minimum data Set and resident assessment instrument on the quality of care plans in Japan. Canadian Journal of Quality in Health Care 1997, 14(3):23-28

28. Fries BE, Hawes $C$, Morris JN, Phillips CD, Mor V, Park PS: Effect of the national resident assessment instrument on selected health conditions and problems. J Am Geriatr Soc 1997, 45(8):994-1001.

29. Phillips CD, Morris JN, Hawes C, Fries BE, Mor V, Nennstiel M, lannacchione $V$ : Association of the resident assessment instrument (RAI) with changes in function, cognition and psychosocial status. J Am Geriatr Soc 1997, 45(8):986-993

30. Phillips $C D$, Zimmerman DR, Bernabei $R$, Jonsson PV: Using the resident assessment instrument for quality enhancement in nursing homes. Age Ageing 1997, 26(2):77-81.

31. Mor V, Intrator O, Fries BE, Phillips CD, Teno J, Hiris J, Hawes C, Morris J: Changes in hospitalization associated with introducing the resident assessment instrument. J Am Geriatr Soc 1997, 45(8):1002-1010.

32. Achterberg WP, Van Campen C, Pot AM, Kerkstra A, Ribbe MW: Effects of the resident assessment instrument on the care process and health outcomes in nursing homes: a review of the literature. Scand J Rehabil Med 1999, 31(3):131-137.

33. Achterberg WP, Holtkamp CCM, Kerkstra A, Pot AM, Ooms ME, Ribbe MW: Improvements in the quality of co-ordination of nursing care following implementation of the resident assessment instrument in Dutch nursing homes. J Adv Nurs 2001, 35(2):268-275.

34. Landi F, Tua E, Onder G, Carrara B, Sgadari A, Rinaldi C, Gambassi G, Lattanzio F, Bernabei R: Minimum data set for home care: a valid instrument to assess frail older people living in the community. Med Care 2000, 38(12):1184-1190.

35. Holtkamp CCM: Effects of the resident assessment instrument on quality of care and quality of life in nursing homes, PhD thesis. Vrije universiteit Amsterdam; 2003. 
36. Zimmerman DR: Improving nursing home quality of care through outcomes data: the MDS quality indicators. Int J Geriatr Psychiatry 2003, 18(3):250-257

37. Boorsma M, Frijters DHM, Knol DL, Ribbe ME, Nijpels G, VanHout HPJ: Effects of multidisciplinary integrated care on quality of care in residential care facilities for elderly people: a cluster randomized trial. Can Med Assoc J 2011, 183(11):E724-E732.

38. Currie W, Finnegan D: Integrating healthcare with information and communications technology. Abingdon: Radcliffe Publishing Ltd; 2009.

39. Kowitlawakul $Y$ : The technology acceptance model: predicting nurses' intention to use telemedicine technology (eICU). Comput Inform Nurs 2011, 29(7):411-418.

40. Watson R: European Union leads way on e-health but obstacles remain. Br Med J 2010, 341:c5195.

41. Genuardi P: User adoption of information technology: implications for application development research, PhD thesis. Georgetown University; 2004

42. Al-Azmi SF, Al-Enezi N, Chowdhury RI: Users' attitudes to an electronic medical record system and its correlates: a multivariate analysis. Health Inf Manag J 2009, 38(2):33-40.

43. Boorsma M, Langedijk E, Frijters DHM, Nijpels G, Elfring T, van Hout HPJ: Implementation of geriatric assessment and decision support residential care homes: facilitating and impeding factors. BMC Health Serv Res 2013, 13:8.

44. Yu P, Li H, Gagnon MP: Health IT acceptance factors in long-term care facilities: a cross-sectional survey. Int J Med Inform 2009, 78(4):219-229.

45. Wills MJ, El-Gayar OF, Bennett D: Examining healthcare professionals' acceptance of electronic medical records using UTAUT. Inf Syst 2008, IX(2):396-401.

46. Venkatesh V, Morris MG, Davis GB, Davis FD: User acceptance of information technology: toward a unified view. MIS Q 2003, 27(3):425-478.

47. Venkatesh $V$, Morris MG: Why don't men ever stop to ask for directions? gender, social influence, and their role in technology acceptance and usage behavior. MIS Q 2000, 24(1):115-139.

48. Venkatesh $V$, Zhang $X$ : Unified theory of acceptance and Use of technology: U.S. vs. China. J Glob Inf Technol Manag 2010, 13(1):5-27.

49. Davis FD: Perceived usefulness, perceived ease of use, and user acceptance of information technology. MIS Q 1989, 13(3):319-340.

50. Bandura A: Social foundations of thought and action: a social cognitive theory. New Jersey: Prentice Hall; 1986.

51. Fishbein M, Ajzen I: Belief, attitude, intention and behavior: an introduction to theory and research. Reading: Addison-Wesley; 1975.

52. Ajzen I: The theory of planned behavior. Organ Behav Hum Decis Process 1991, 50(2):179-211.

53. Taylor S, Todd PA: Understanding information technology usage: a test of competing models. Inf Syst Res 1995, 6(4):144-176.

54. Thompson RL, Higgins CA, Howell JM: Personal computing: toward a conceptual model of utilization. MIS Q 1991, 15(1):124-143.

55. Taylor S, Todd PA: Assessing IT usage: the role of prior experience. MIS Q 1995, 19(2):561-570.

56. Rogers E: Diffusion of innovations. New York: Free Press; 1995.

57. Davis FD, Bagozzi RP, Warshaw PR: Extrinsic and intrinsic motivation to use computers in the workplace. J App/ Soc Psycho/ 1992, 22(14):1111-1132.

58. Venkatesh V, Sykes TA, Zhang X: 'Just what the doctor ordered': a revised UTAUT for EMR system adoption and use by doctors. System Sciences 2011:1-10

59. Brown SA, Dennis AR, Venkatesh V: Predicting collaboration technology use: integrating technology adoption and collaboration research. J Manag Inf Syst 2010, 27(2):9-53.

60. Johns $\mathrm{G}$ : The essential impact of content on organizational behavior. Acad Manage Rev 2006, 31(2):386-408.

61. Griffin MA: Specifying organizational contexts: systematic links between contexts and processes in organizational behavior. J Organ Behav 2007, 28:859-863

62. Duyck P, Pynoo B, Devolder P, Voet T, Adang L, Vercruysse J: User acceptance of a picture archiving and communication system. Methods Inf Med 2008:149-156.

63. de Veer AJE, Fleuren MAH, Bekkema N, Francke AL: Successful implementation of new technologies in nursing care: a questionnaire survey of nurse-users. BMC Med Inform Decis Mak 2011, 11:67.

64. Chau PYK, Hu PJ-H: Investigating healthcare professionals' decisions to accept telemedicine technology: an empirical test of competing theories. Information \& Management 2002, 39(4):297-311.
65. Morris JN, Fries BE, Bernabei R, Steel K, Ikegami N, Carpenter I, Gilgen R, DuPasquier J-N, Frijters D, Henrard J-C, Hirdes JP, Belleville-Taylor P: interRAl home care (version 09): assessment manual: users guide for the interRAI HC assessment form. InterRAl; 2006.

66. Morris JN, Belleville-Taylor P, Fries BE, Hawes C, Murphy K, Mor V, Nonemaker S, Phillips CD: InterRAl long-term care facility (version 09). InterRAl: Guide for use of the interRAI LTCF assessment form; 2006.

67. Gray L, Berg K, Bernabei R, Blasco S, Carpenter Gl, Finne-Soveri H, Fries BE, Hirdes JP, Jonsson P, Morris JN, Murphy K, Steel K, Nonemaker S, Rabinowitz T, Topinkova E: Training manual and resource guide: interRAl acute care: guide for use of the interRAI AC assessment form (version 09). InterRAl; 2006.

68. Declercq A, Flamaing J, Gosset C, Milisen K, Moons P, Collard J, Delye S, Devriendt E, Gillain N, Londot A, Van Eenoo L, Vanneste D, Vesentini L, Wellens $\mathrm{N}$ : BelRAI VI - wetenschappelijk onderzoek met betrekking tot de pilootprojecten voor het transmuraal gebruik van het BelRAl-instrument. Brussel: FOD Volksgezondheid, Veiligheid van de Voedselketen en Leefmilieu; 2011.

69. De Almeida MJ, Van Durme T, Macq J, Declercq A: Interventions to delay institutionalization of frail older persons: design of a longitudinal study in the home care setting. BMC Public Health 2012, 12:1.

70. Oshlyansky L, Cairns P, Thimbleby H: Validating the unified theory of acceptance and Use of technology (UTAUT) tool cross-culturally, Proceedings of the 21st British $\mathrm{HCl}$ group annual conference on people and computers: $\mathrm{HCl}$... but not as we know it: volume 2;Swinton. British Computer Society Swinton UK; 2007:83-86.

71. Guillemin F, Bombardier C, Beaton D: Cross-cultural adaptation of health-related quality of life measures: literature review and proposed guidelines. J Clin Epidemiol 1993, 46(12):1417-1432.

72. QuestionPro. [http://www.questionpro.com]

73. Dillman DA: The design and administration of mail surveys. Annu Rev Sociol 1991, 17:225-249.

74. Chin WW: PLS-graph users' guide: version 3.0. In Edited by Chin WW. ; 2001

75. Straub D, Boudreau M-C, Gefen D: Validation guidelines for IS positivist research. Commun Assoc Inf Syst 2004, 14:380-426

76. Gefen D, Straub DW, Boudreau M-C: Structural equation modeling and regression: guidelines for research practice. Commun Assoc Inf Syst 2000, 4:1-79.

77. Haenlein M, Kaplan AM: A beginner's guide to partial least squares analysis. Underst Stat 2004, 3(4):283-297.

78. Chin WW, Marcolin BL, Newsted PR: A partial least squares latent variable modeling approach for measuring interaction effects: results from a Monte Carlo simulation study and voice mail emotion/adoption study. In Proceedings of the international conference on information systems: 16-18 december 1996; Cleveland, Ohio. Edited by DeGross JI, Jarvenpaa S, Srinivasan A.; 1996:21-41.

79. Vinzi VE, Trinchera L, Amato S: PLS path modeling: from foundations to recent developments and open issues for model assessment and improvement. In Handbook of partial least squares. Edited by Vinzi E, Chin WW, Henseler J, Wang H. Berlin, Heidelberg: Springer handbooks; 2010:47-83.

80. Gefen D, Straub D: A practical guide to factorial validity using PLS-graph: tutorial and annotated example. Commun Assoc Inf Syst 2005, 16:91-109.

81. Chin WW: Frequently asked questions - partial least squares \& PLS-graph. http://disc-nt.cba.uh.edu/chin/plsfaq/plsfaq.htm.

82. Kuechler WL, McLeod A, Simkin MG: Why don't more students major in IS? Decis Sci J Innov Educ 2009, 7(2):463-488

83. Nunnally JC: Psychometric theory. 2nd edition. New York: McGraw-Hill; 1978.

84. Nunnally JC, Bernstein $\mathrm{H}$ : Psychometric theory. 3rd edition. New York: McGraw-Hill; 1994

85. Fornell C, Larcker DF: Evaluating structural equation models with unobservable variables and measurement error. J Mark Res 1981, 18(1):39-50.

86. Chin WW: The partial least squares approach for structural equation modeling. In Modern methods for business research. Edited by Marcoulides GA. New York: Lawrence Erlbaum Associates; 1998:295-336.

87. Declercq A, Gosset C, Wellens N, Collard J, Filee D, Londot A, Polome L, Sprenghetti N, Moons P, Milisen K, Van Audenhove C: Actie-onderzoeknaar het gebruik van het RAl-instrument in de geriatrische dagziekenhuizen, de rust- en verzorgingstehuizen, de dagcentra en de geïntegreerde diensten voor de thuiszorg. Brussel: FOD Volksgezondheid, Veiligheid van de Voedselketen en Leefmilieu; 2007.

88. Declercq A, Gosset C, Paepen B, De Almeida Mello J, Vanneste D, Detroyer E, Milisen K, Moons P, Berden J, Collard J, Londot A, Schumacher I, Demul N, Piette N, Joiris T, Gillain N, Van Audenhove C: Actieproject BelRAl II: 
Haalbaarheid van de RAl-methode in België. Brussel: FOD Volksgezondheid, Veiligheid van de Voedselketen en Leefmilieu; 2008.

89. Declercq A, Gosset C, Paepen B, De Almeida Mello J, Vanneste D, Detroyer E, Spruytte N, De Vliegher K, Berden J, Degey S, Philippet C, Tancredi A, Lepère C, Renard F, Gillain N, Van Audenhove C: Actieproject BelRAl III: Haalbaarheid van de RAl-methode in België. Brussel: FOD Volksgezondheid, Veiligheid van de Voedselketen en Leefmilieu; 2009.

90. Declercq A, Gosset C, Milisen K, Moons P, Flamaing J, Vesentini L, Vanneste D, Roovers S, Grevendonck L, Van Eenoo L, De Almeida Mello J, Wellens N, Devriendt E, Deschodt M, Delye S, Renard F, Grauwels N, Collard J, Londot J, Tancredi A, Gillain N, Berden J, Paepen B, Vanbockryck F: BelRAI 2010 - Tussentijds rapport. Brussel: FOD Volksgezondheid, Veiligheid van de Voedselketen en Leefmilieu; 2010.

91. Declerca A, Gosset C, De Almeida Mello J, Detroyer E, Spruytte N, Vanneste D, Vesentini L, Grevendonck L, Roovers S, Paepen B, Berden J, Collard J, Grauwels N, Londot A, Lepère C, Michel J, Renard F, Schumacher I, Tancredi A, Gillain N, Wellens N, Milisen K, Moons P, Van Audenhove C: BelRAI IV: actie-onderzoek ter voorbereiding van de implementatie van de RAl-methode in België. Brussel: FOD Volksgezondheid, Veiligheid van de Voedselketen en Leefmilieu; 2010

doi:10.1186/1472-6947-13-129

Cite this article as: Vanneste et al.: Healthcare professionals' acceptance of BelRAl, a web-based system enabling person-centred recording and data sharing across care settings with interRAl instruments: a UTAUT analysis. BMC Medical Informatics and Decision Making 2013 13:129.

\section{Submit your next manuscript to BioMed Central and take full advantage of:}

- Convenient online submission

- Thorough peer review

- No space constraints or color figure charges

- Immediate publication on acceptance

- Inclusion in PubMed, CAS, Scopus and Google Scholar

- Research which is freely available for redistribution 